United States, so that there will be a wide welcome for the way in which the Political Quarterly has given over its spring issue entirely to a symposium on what it calls the politics of science. Even those who consider that the whole enterprise has somehow fallen short of the declared objective of helping "to reconcile the interests of science with the needs of society" will find pleasure in much of what the contributors have to say. Dr. H. M. Finniston is particularly worth reading on the relationship-or lack of relationship-between the universities and industry; in the present climate, what he has to say will make more friends than enemies. Yet the overall impression left by this symposium is of a miscellany of arguments advanced by different people from different points of view. Only Professor J. D. Bernal comes close to a definition of the kinds of questions on which political decisions can critically affect the health, or otherwise, of science and technology-the scale on which resources should be allocated to research and development, the importance that should be attached to defence research and the allocation of resources to higher education, for example -and he is compelled on several occasions to offer not answers but reasons why answers will be difficult to find. Nobody should be surprised if the readers of the Political Quarterly are persuaded by the experience that the concept of the politics of science is nebulous, to say the best of it.

To say this is not to suggest that the political implications of science and technology, and the scientific implications of politics, are unimportant or nonexistent, but that the relationship between them is a good deal more complicated than is commonly allowed. Failure to acknowledge the full complexity of the interaction is the root of a good many fashionable fallacies. Thus there is no certain assurance that the best way of obtaining a greater stock of skilled engineers is to introduce more applied science (or more science of any kind) into the secondary schools. Although there is no doubt that science and technology are at the roots of the modern industries with which advanced societies create wealth, it does not follow that more research and development will bring more wealth. In Britain, for example, there is at least a case for saying that the comparatively slow rate of economic growth in the past fifteen years is not a consequence of deficiencies in technology but of a failure to exploit new techniques of management to the full. (On this reading, the brain drain is an empirical proof of a surplus of scientists and engineers, which is not as outrageous an interpretation as it may seem; scientists and engineers would not emigrate in such large numbers if their employers paid them enough to stay at home.) Certainly there is no case for thinking that all research and development is equally valuable, which implies that the gross yardsticks inevitably used for comparing the scale of scientific effort in different places may not be reliable. The Political Quarterly itself argues that research aimed at prestige and not economic benefit is a waste of money, which only goes to show that accountants have very little to say about the scale on which efforts should be deployed. It follows that politicians should not be surprised if their reading of this symposium leaves them with the impression that the politics of science is not a simple monster but a hydra. That is not an illusion but the truth.

\section{HUNTING THE QUASAR}

THe hunt for the quasar goes on. This week (page 239) it is Professor McCrea. Last week it was Professor McVittie, Dr. Stabell (Nature, 213, 133) and Dr. Verschuur (ibid., 164). Next week-who knows? The only certainty is that it will be some time before there is a simple answer to one of the most teasing problems for several decades. At least a part of the reason for interest in quasars is that experimental information is so meagre that people are necessarily hard pressed to tell a good answer from one that is merely plausible. It is just within the bounds of possibility that one of these days somebody may point to some well established truth with such conviction that everybody will know what quasars are.

In the meantime, it is only seemly to recall that theorists are rarely so much at a loss as the cosmologists are now when confronted by the observational evidence on quasars. For four years it has been plain that quasars could not be written off as intense radio galaxies, if only because not all of them are radio sources. Their frequently gigantic red-shifts imply great distance, but their variability from year to year and even from month to month implies dimensions which are small (in light years or light months) and therefore, probably, a location somewhere within the local galaxy. How is this apparent conflict to be resolved? In the long run there will be data substantial enough to guide people more certainly to a conclusion. But it is also possible that there may be more to wring out of the observations already on record, which is why there is a continual search for some suggestive irregularity in the data-anisotropy, perhaps, or a significant departure from the relationship between the brightness of quasars and their frequency that would be expected from the hypothesis that the universe is always everywhere the same. This, too, is why people are searching for ways in which comparatively familiar cosmological bits and pieces could be made to behave like quasars. Some theories involve comparatively local quasars, and then have to deploy great ingenuity on an explanation of how spectral lines can be shifted towards the red, presumably as a relativistic consequence of a gravitational attraction, without the celestial object concerned being so dense that it prevents the escape of radiation. Other theories involve more distant objects. But nobody knows which model will succeed, and how soon. And nobody knows how radical a revision of accepted doctrines a decent model of quasars will require. If astronomers should fail to sleep for excitement-or even from anxiety-society should indulge them. 